\title{
Editorial
}

\section{Merkel cell carcinoma: what is next?}

\author{
Thomas S. Bander, $\mathrm{MD}^{1}$ and Kelly L. Harms, MD, $\mathrm{PhD}^{2}$
}

NV erkel cell carcinoma $(\mathrm{MCG})$ is a rare and aggressive cutaneous neuroendocrine carcinoma which was first described in 1972. MCC typically presents as a red to violaceous papule or nodule on sun-exposed skin of older patients or those who are immunosuppressed. The primary lesion often grows rapidly over 2-3 months and has a higher risk of metastasis to nodal basins and distant sites than melanoma. Due to the rarity of the disease, its etiology was unclear until a pivotal discovery of viral sequences in tumor samples. In 2008, this polyomavirus was identified and named Merkel cell polyomavirus $(\mathrm{MCPyV}) .{ }^{1}$ Since then, research into disease pathogenesis, prognostic markers, and treatment paradigms has flourished. ${ }^{2}$

MCG is currently thought to arise from MCPyV- or ultraviolet (UV)-mediated DNA mutations. ${ }^{1,3,4,5} \mathrm{MCPyV}$ is a ubiquitous virus, and most people are exposed in childhood. Tumorigenesis via $\mathrm{MCPyV}$ is thought to occur in association with two rare events: integration of viral genome into host genome and truncation of the viral large $\mathrm{T}$ antigen gene product which abrogates viral replication. It is estimated that up to $80 \%$ of MCG are associated with MCPyV; however, the percentage varies and has been reported to be lower in Australia likely due to high UV index and more prevalent UV-associated pathogenesis. ${ }^{6}$ To date, studies have been mixed on the prognosis of viral positivity, but the largest study suggests it is a positive prognostic factor. ${ }^{7}$
Historically, management of stage IV disease involved cytotoxic chemotherapy, and responses were not durable. In 2016, it was shown that metastatic MCC has a durable response to immune checkpoint inhibition, transforming the medical management of advanced disease. ${ }^{8,9,10}$ Importantly, the prognosis of MCG is now improved and historical data will be just that - history. Future research using large national databases may help compare diagnosis and management before and after the availability of immunotherapy, but it will take time to collect this new data.

Now that we have successful treatment options for patients with stage IV disease, we must continue to refine our treatment paradigm. Many questions remain. How do we minimize side effects while maintaining therapeutic benefit? Will new prognostic factors demonstrate enough significance to include in staging systems? With improved response to therapy, we may turn our attention to factors that influence recurrence. What are the biologic predictors of recurrence? Will adjuvant immunotherapy prevent recurrence? What tumor burden is necessary for adjuvant immunotherapy to be effective? What is the role of neoadjuvant immunotherapy? Carefully designed clinical trials and other studies will be necessary to address unmet needs in therapy and further our understanding of the natural history of this disease. 
1. Feng H, Shuda M, Chang Y, Moore PS. Clonal integration of a polyomavirus in human Merkel cell carcinoma. Science. 2008 Feb 22;319(5866):1096-100.

2. Harms PW, Harms KL, Moore PS, DeCaprio JA, Nghiem P, Wong MKK, Brownell I; International Workshop on Merkel Cell Carcinoma Research (IWMCG) Working Group. The biology and treatment of Merkel cell carcinoma: current understanding and research priorities. Nat Rev Clin Oncol. 2018 Dec;15(12):763-776.

3. Verhaegen ME, Mangelberger D, Harms PW, et al. Merkel Cell Polyomavirus Small T Antigen Initiates Merkel Cell Carcinoma-like Tumor Development in Mice. Cancer Res. 2017 Jun 15;77(12):31513157.

4. Harms PW, Vats P, Verhaegen ME, et al. The Distinctive Mutational Spectra of Polyomavirus-Negative Merkel Cell Carcinoma. Cancer Res. 2015 Sep 15;75(18):3720-3727.

5. Wong SQ, Waldeck K, Vergara IA, et al. UV-Associated Mutations Underlie the Etiology of MCV-Negative Merkel Cell Carcinomas. Cancer Res. 2015 Dec 15;75(24):5228-34.
6. Garneski KM, Warcola AH, Feng Q, et al. Merkel cell polyomavirus is more frequently present in North American than Australian Merkel cell carcinoma tumors. J Invest Dermatol. 2009 Jan;129(1):246-8.

7. Moshiri AS, Doumani R, Yelistratova L, et al. Polyomavirus-Negative Merkel Cell Carcinoma: A More Aggressive Subtype Based on Analysis of 282 Cases Using Multimodal Tumor Virus Detection. J Invest Dermatol. 2017 Apr;137(4):819-827.

8. Nghiem PT, Bhatia S, Lipson EJ, et al. PD-1 Blockade with Pembrolizumab in Advanced Merkel-Cell Carcinoma. N Engl J Med. 2016 Jun 30;374(26):2542-52.

9. Nghiem P, Bhatia S, Lipson EJ, et al. Durable Tumor Regression and Overall Survival in Patients With Advanced Merkel Cell Carcinoma Receiving Pembrolizumab as First-Line Therapy. J Clin Oncol. 2019 Mar 20;37(9):693-702

10. D'Angelo SP, Russell J, Lebbé C, et al. Efficacy and Safety of First-line Avelumab Treatment in Patients With Stage IV Metastatic Merkel Cell Carcinoma: A Preplanned Interim Analysis of a Clinical Trial. J AMA Oncol. 2018 Sep 1;4(9):e180077. 